\title{
Análise Comparativa da Variabilidade Patogênica de Uromyces appendiculatus em Algumas Regiões Brasileiras
}

\author{
Thiago Lívio P. O. de Souza ${ }^{1,2 *}$, Ana Lília Alzate-Marin ${ }^{1,3}$, Maurilio A. Moreira ${ }^{1,4}$ \& Everaldo G. de Barros ${ }^{1,5}$ \\ ${ }^{1}$ Instituto de Biotecnologia Aplicada à Agropecuária - BIOAGRO; ${ }^{2}$ e-mail: thiagolivio@vicosa.ufv.br; ${ }^{3} \mathrm{e}$-mail: \\ anaalzatem@yahoo.com.br; ${ }^{4}$ Departamento de Bioquímica e Biologia Molecular, e-mail: moreira@ufv.br; ${ }^{5}$ Departamento de \\ Biologia Geral, e-mail: ebarros@ufv.br; Universidade Federal de Viçosa, CEP 36570-000, Viçosa, MG, fax: (31) 3899-2864
}

(Aceito para publicação em 01/02/2005)

Autor para correspondência: Everaldo G. de Barros

SOUZA, T.L.P.O., ALZATE-MARIN, A.L., MOREIRA, M.A. \& BARROS, E.G. Análise comparativa da variabilidade patogênica de Uromyces appendiculatus em algumas regiões brasileiras. Fitopatologia Brasileira 30:143-149. 2005.

\section{RESUMO}

A ferrugem do feijoeiro comum (Phaseolus vulgaris), incitada pelo fungo Uromyces appendiculatus, é uma das mais importantes doenças que afetam essa cultura. Trabalhos anteriores demonstraram a ampla variabilidade patogênica de $U$. appendiculatus no Brasil. No entanto, o uso de distintos grupos de cultivares diferenciadoras em tais trabalhos dificulta a análise comparativa e a identificação de fontes de resistência de amplo espectro. Assim, os objetivos deste trabalho foram: 1) caracterizar sete isolados de U. appendiculatus, coletados em diferentes regiões do estado de Minas Gerais, frente às 19 cultivares diferenciadoras para ferrugem, adotadas no "The Bean Rust Workshop", realizado em 1983, em Porto Rico, e 2) comparar os padrões de resistência/suscetibilidade obtidos, com aqueles apresentados frente a patótipos isolados nos estados de Santa Catarina, Rio Grande do Sul e Goiás, visando identificar fontes de resistência de amplo espectro. Os sete isolados coletados em Minas Gerais foram classificados com sete patótipos distintos. As cultivares diferenciadoras com os maiores espectros de resistência foram 'Redlands Pioneer', 'California Small White 643', 'Brown Beauty', 'AxS 37' e 'Compuesto Negro Chimaltenango'. Portanto, apesar da exclusão das cultivares California Small White 643, AxS 37 e Brown Beauty da nova série diferenciadora internacional proposta em 2002, na África do Sul, recomenda-se adicionar estas cultivares nas futuras caracterizações de patótipos a serem realizadas no Brasil, como um modo de monitorar a variabilidade patogênica de populações de $U$. appendiculatus nas regiões produtoras.

Palavras-chave adicionais: Phaseolus vulgaris, ferrugem do feijoeiro, fontes de resistência.

\begin{abstract}
Comparative analysis of the pathogenic variability of Uromyces appendiculatus in some regions of Brazil

Common bean (Phaseolus vulgaris) rust, incited by Uromyces appendiculatus, is among the most important diseases affecting this culture. Several works have demonstrated the extensive pathogenic variability of $U$. appendiculatus in Brazil. However, the use of distinct sets of differential cultivars prevents the comparison among the data obtained and the identification of sources with ample resistance spectra. The objectives of this work were: 1) to characterize seven U. appendiculatus isolates collected in different regions of the state of Minas Gerais in relation to the 19 rust differential cultivars defined in the "The Bean Rust Workshop" in 1983, in Porto Rico, and 2) to compare the resistance/susceptibility patterns obtained with those reported with isolates collected in Santa Catarina, Rio Grande do Sul and Goiás, to identify sources with ample resistance spectra. The seven isolates collected in the state of Minas Gerais were classified as seven different pathotypes. The differential cultivars with the largest resistance spectra were 'Redlands Pioneer', 'California Small White 643', 'Brown Beauty', 'AxS 37' and 'Compuesto Negro Chimaltenango'. Despite the fact that the cultivars California Small White 643, AxS 37 and Brown Beauty have been excluded from the new differential series proposed in 2002, in South Africa, we strongly recommend that these three cultivars should also be characterized in future studies in Brazil as a mean of monitoring the pathogenic variability of U. apppendiculatus populations in bean growing regions.
\end{abstract}

Additional keywords: Phaseolus vulgaris, common bean rust, sources of resistance.

\section{INTRODUÇÃO}

A ferrugem do feijoeiro-comum (Phaseolus vulgaris L.), cujo agente causal é o fungo Uromyces appendiculatus (Pers.) Unger [sin. U. phaseoli (Reben) Wint.], pode acarretar sérios prejuízos à cultura, principalmente entre os meses de abril a julho, quando são observadas, nas principais regiões

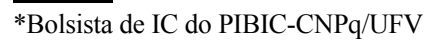

produtoras, temperaturas amenas e ocorrência de orvalho (Paula Júnior \& Zambolim, 1998). Lindgren et al. (1995) estimaram que a cada $1 \%$ de aumento na severidade da ferrugem, ocorre um decréscimo de produtividade de cerca de $19 \mathrm{Kg} / \mathrm{ha}$.

O fungo $U$. appendiculatus é um parasita obrigatório que apresenta alta variabilidade fisiológica (Cumins, 1978; Groth \& Ozmon, 1994), o que dificulta os trabalhos de melhoramento visando resistência à doença (Faleiro et al., 
1999a; Santos \& Rios, 2000). No Brasil, extensa variabilidade deste fungo nos estados do Rio Grande do Sul, Santa Catarina e Minas Gerais foi relatada (Dias \& Costa, 1968; Junqueira Netto et al., 1969; Agustin \& Costa, 1971; Coelho \& Chaves, 1975; Carrijo et al., 1980; Vieira, 1988). No entanto, a dificuldade na comparação dos patótipos identificados, devido aos diferentes critérios utilizados na sua classificação, impediu o conhecimento real da variabilidade patogênica do fungo no país.

Visando contornar as dificuldades nos estudos da variabilidade deste patógeno, foi realizado em Porto Rico, em 1983, o "The Bean Rust Workshop", onde foi definido o emprego de 19 cultivares diferenciadoras para classificar os patótipos de $U$. appendiculatus e uma escala padrão de avaliação das reações à doença (Stavely et al., 1983). Usando esta metodologia, foram identificados 94 patótipos em diferentes partes do mundo (Pastor-Corrales, 2001). Entretanto, na reunião de Porto Rico, não ficou estabelecido um sistema de denominação dos patótipos. No Brasil, Santos \& Rios (2000) fizeram o único trabalho de caracterização de isolados brasileiros de $U$. appendiculatus usando a série diferenciadora proposta, utilizando isolados provenientes de Goiás, Santa Catarina e Rio Grande do Sul. Mora-Nunez et al. (1992) e Faleiro et al. (1999a), no entanto, utilizaram oito das 19 cultivares diferenciadoras propostas (Kentucky Wonder 814, Early Gallatin, 51051, NEP-2, Ecuador 299, Pinto Olathe, Mexico 309 e Redlands Pioneer) e um outro sistema de classificação para caracterizar isolados coletados no estado de Minas Gerais. Com esta metodologia, 13 patótipos foram identificados (Faleiro et al., 1999a). No entanto, o uso de critérios alternativos dificultou a comparação do espectro de virulência destes patótipos com outros identificados e caracterizados por diferentes grupos de pesquisa tanto do Brasil como de outros países.

Assim, o presente trabalho objetivou caracterizar, frente às 19 cultivares diferenciadoras, os sete isolados de $U$. appendiculatus coletados no estado de Minas Gerais por Faleiro et al. (1999a), e comparar os espectros de resistência das cultivares diferenciadoras com aqueles relatados por Santos \& Rios (2000). Além disso, o trabalho teve como objetivo identificar fontes de resistência de amplo espectro, as quais poderão ser utilizadas como genitores doadores em programas de melhoramento que visem o desenvolvimento de cultivares resistentes a esta doença.

\section{MATERIAL E MÉTODOS}

\section{Material genético}

As sementes das 19 cultivares diferenciadoras para ferrugem do feijoeiro foram fornecidas pelo Centro Internacional de Agricultura Tropical (CIAT, Cali, Colômbia). Redlands Pioneer e Brown Beauty são cultivares pertencentes ao pool gênico Andino, enquanto que as cultivares California Small White 643, Pinto 650, Kentucky Wonder 814, Ecuador 299, México 235, Olathe, AxS 37, NEP-2, Aurora, 51051 e Compuesto Negro Chimaltengo pertencem ao pool gênico
Mesoamericano. Já as cultivares US 3, Kentucky Wonder 765, Kentucky Wonder 780, Golden Gate Wax, Early Gallatin e México 309 são derivadas de cruzamentos entre genitores pertencentes aos dois pools gênicos, sendo referidas neste trabalho como pertencentes ao pool Andino/Mesoamericano. As testemunhas resistente (cv. Ouro Negro) e suscetível (cv. US Pinto 111) foram obtidas do Banco de Germoplasma do Instituto de Biotecnologia Aplicada à Agropecuária da Universidade Federal de Viçosa (BIOAGRO/UFV). Para uniformizar o poder germinativo das sementes, todos as cultivares foram multiplicadas em condições de casa de vegetação.

\section{Origem e obtenção de isolados monopustulares de $U$. appendiculatus}

Os isolados usados no presente trabalho foram coletados no estado de Minas Gerais, nas regiões de Coimbra (isolados 1 e 4), Lavras (isolado 6), Lambari (isolados 9 e 10) e Patos de Minas (isolados 11 e 12), e preservados na micoteca do programa de melhoramento do feijoeiro do BIOAGRO/ UFV, sob condições controladas (temperatura de $5 \pm 1{ }^{\circ} \mathrm{C}$, $<50 \%$ de umidade relativa e em ausência de luz). Eles estão incluídos no grupo de 13 patótipos previamente caracterizados por Faleiro et al. (1999a).

Na obtenção de isolados monopustulares foi empregada a cultivar US Pinto 111 e a metodologia descrita por Carrijo et al. (1980), utilizando-se uma concentração menor que a usual de inóculo $\left(1,5 \times 10^{4}\right.$ uredosporos $\left./ \mathrm{ml}\right)$, com o objetivo de se obter pústulas separadas.

Sementes da cultivar US Pinto 111, suscetível universal a ferrugem, foram semeadas em casa de vegetação. Dez dias após o plantio, quando as folhas primárias apresentavam aproximadamente $2 / 3$ do seu desenvolvimento completo, o inóculo de cada um dos sete patótipos, separadamente, foram suspensos em água destilada contendo $0,05 \%$ de Tween $20 \mathrm{e}$ aspergido na face adaxial das folhas, com o auxílio de um atomizador De Vilbiss no 15, acionado por um compressor elétrico. Após inoculação e rápida secagem ao ar, as plantas foram transferidas para câmara de nevoeiro $\left(20 \pm 1^{\circ} \mathrm{C}\right.$ e $>95 \%$ de umidade relativa), onde permaneceram por 48 horas, sob fotoperíodo controlado de 12 horas. Para evitar contaminação entre os isolados, para cada patótipo foi utilizada uma célula da câmara de nevoeiro. Após esse período, as plantas de cada ensaio foram novamente transferidas para a casa de vegetação $\left(20 \pm 5^{\circ} \mathrm{C}\right)$ e isoladas por barreiras físicas construídas com lâminas de isopor, onde permaneceram por aproximadamente 15 dias, até a completa formação das pústulas (Faleiro et al., 1999a). Nesta fase, os uredosporos provindos de uma única pústula de cada um dos patótipos (isolados monopustulares) foram coletados cuidadosamente. Uma única pústula de cada patótipo gerou o isolado representativo do mesmo, constituindo sete isolados puros com virulência garantida. Esse procedimento foi realizado para reduzir a possibilidade de futuras interpretações errôneas nas avaliações da interação entre os patótipos e as cultivares diferenciadoras, as quais poderiam ter sido provocadas por contaminação durante as 
Ánálise comparativa da variabilidade patogênica de Uromyces appendiculatus...

multiplicações do fungo anteriormente realizadas.

Os isolados monopustulares obtidos foram multiplicados na cultivar US Pinto 111 por meio de inoculações sucessivas, conforme a metodologia já descrita, usando a concentração de inóculo padrão $\left(2,0 \times 10^{4}\right.$ uredosporos $\left./ \mathrm{ml}\right)$. Os uredosporos coletados foram armazenados em ampolas de vidro recobertas com papel alumínio, evitando o acesso da luz, e posteriormente acondicionados sob temperatura de $5 \pm$ $1^{\circ} \mathrm{C}$ e $<50 \%$ de umidade relativa.

\section{Inoculação do patógeno e avaliação da doença nas cultivares diferenciadoras}

Sete ensaios foram conduzidos, separadamente, para caracterizar os sete isolados de U. appendiculatus, frente às 19 cultivares diferenciadoras. Em cada ensaio, 12 sementes de cada uma das 19 diferenciadoras foram plantadas em bandejas plásticas juntamente com as cultivares testemunhas Ouro Negro e US Pinto 111, de modo que três bandejas comportassem as 21 cultivares (sete cultivares por bandeja). Dez dias após a semeadura, cada patótipo testado foi inoculado, separadamente, nas plantas de cada ensaio, utilizando-se uma concentração de esporos de $2,0 \times 10^{4}$ uredosporos $/ \mathrm{ml}$, seguindo a metodologia já descrita.

A avaliação do grau de infecção da doença foi baseada na escala de avaliação proposta no "The Bean Rust Workshop" (Stavely et al., 1983), considerando seis graus de reação: 1- ausência de pústulas; 2- manchas necróticas sem esporulação; 3- pústulas esporulando com diâmetro $<300 \mu \mathrm{m}$; 4- pústulas esporulando com diâmetro de $300 \mu \mathrm{m}$ a $499 \mu \mathrm{m}$; 5- pústulas esporulando com diâmetro de $500 \mu \mathrm{m}$ a $800 \mu \mathrm{m}$; 6- pústulas esporulando com diâmetro $>800 \mu \mathrm{m}$. O grau de reação foi determinado mediante observação visual das pústulas na face adaxial das folhas primárias, sendo utilizado, como auxílio nas observações, um diagrama de representação gráfica, idealizado por Castaño (1985). Para que os resultados deste trabalho fossem comparados com os resultados obtidos por Santos \& Rios (2000), adotou-se o mesmo critério de avaliação da doença adotado por aqueles autores. Todos os graus de reação observados foram registrados em ordem decrescente de prevalência, relacionando-se para cada cultivar tanto o grau predominante quanto os presentes em menor freqüência.

\section{Análise comparativa entre espectros de resistência de isolados das diferentes origens geográficas}

Para realizar a análise comparativa dos espectros de resistência observados no presente trabalho com os relatados por Santos \& Rios (2000), as notas originais foram convertidas em reações de resistência e suscetibilidade, pois ambas as avaliações foram realizadas seguindo a mesma escala, adotada no "The Bean Rust Workshop" (Stavely et al., 1983). As plantas que apresentaram graus de reação de 1 a 3 foram considerados resistentes (-) e as que apresentaram graus de 4 a 6 , suscetíveis (+). A única exceção a este critério foi quando a reação de uma cultivar a um isolado apresentou nota 3 como a mais prevalecente seguida da nota 6 . Neste caso a cultivar foi considerada como suscetível (+).

\section{RESULTADOS E DISCUSSÃO}

Os resultados das inoculações dos sete isolados de $U$. appendiculatus provenientes de Minas Gerais, nas 19 cultivares diferenciadoras, mostraram que as cultivares Mesoamericanas California Small White 643, Ecuador 299, Mexico 235, Compuesto Negro Chimaltenango e Ouro Negro (testemunha) foram resistentes a todos os isolados testados. O mesmo não foi observado na cultivar Andina Redlands Pioneer, e na Andina/Mesoamericana Mexico 309. Brown Beauty (Andina) foi resistente a seis isolados e suscetível apenas ao isolado 6. Por outro lado, as cultivares Pinto 650, Kentucky Wonder 814, Aurora e a testemunha US Pinto 111 (todas de origem Mesoamericana) e as cultivares US 3, Golden Gate Wax e Early Gallatin (Andino/Mesoamericanas), foram suscetíveis a todos os isolados desta região (Tabela 1). As informações relacionadas às fontes de resistência California Small White 643, Mexico 235, Compuesto Negro Chimaltenango e Brown Beauty ainda não tinham sido relatadas, uma vez que estas cultivares não constavam na lista das oito diferenciadoras utilizadas na caracterização realizada por Faleiro et al. (1999a).

Assim como na análise realizada por Faleiro et al. (1999a), verificou-se com os resultados deste trabalho, que os sete isolados provenientes de Minas Gerais classificaramse em sete patótipos distintos (Tabelas 1 e 2). Entretanto, quando as duas avaliações são comparadas, diferentes reações a esses isolados foram observadas em algumas cultivares comuns às duas séries diferenciadoras utilizadas. Cinco das oito cultivares apresentaram diferentes reações com relação a alguns patótipos nas duas avaliações realizadas. Diferentes reações foram observadas na cultivar Pinto Olathe (aos patótipos 1, 4, 6, 9, 10 e 11) e na cultivar NEP -2 (aos patótipos $1,6,10$ e 12). A maioria das diferenças referiu-se à definição das notas 3 ou 4, que caracterizam reações limiares entre resistência (notas de 1 a 3 ) e susceptibilidade (notas de 4 a 6). Faleiro et al. (1999a) registraram reações de suscetibilidade das cultivares Mexico 309 e Redlands Pioneer, aos patótipos 1, 4, 6 e 11, 12, respectivamente, enquanto no presente trabalho essas cultivares foram classificadas como resistentes a estes mesmos patótipos (Tabela 2). Os cultivares que conservaram o mesmo espectro em ambos os trabalhos foram Ecuador 299 (resistente) e Kentucky Wonder 814 e Early Gallatin (suscetíveis). A alta variabilidade patogênica das populações de $U$. appendiculatus já foi verificada por vários autores (Junqueira Neto et al., 1969; Stavely, 1984; Vieira, 1988; Mora-Nuñes et al., 1992; Faleiro et al., 1999a; Santos \& Rios, 2000). Porém, no presente trabalho foram observadas variações em populações do patógeno que são constantemente multiplicadas sob condições controladas. Uma possível causa dessa discrepância seria o novo isolamento monospórico realizado neste trabalho. Outra possível causa estaria relacionada à subjetividade da escala de classificação utilizada, como já mencionado por Faleiro et al. (1999b), sobretudo na 
classificação de plantas com graus de reação 3 ou 4, o que, nesta escala, constitui uma difícil diferenciação entre as classes de resistência ou susceptibilidade. Pequenas mudanças nas concentrações do inóculo também têm sido consideradas como possíveis causas destas diferenças (Stavely, 1984).

$\mathrm{Na}$ análise comparativa das reações das 19 cultivares diferenciadoras frente aos sete isolados provenientes de Minas Gerais (presente trabalho) e as trinta e quatro coletadas em Santa Catarina, Rio Grande do Sul e Goiás (Santos \& Rios, 2000), pode-se observar que os genes de origem Mesoamericana das cultivares California Small White 643, AxS 37 e Compuesto Negro Chimaltengo conferem resistência, respectivamente, a 40, 39 e 35 dos 41 isolados de $U$. appendiculatus analisados (Tabela 2). Compuesto Negro Chimaltengo e AxS 37 estão também entre as cultivares mais resistentes aos 94 patótipos mantidos na coleção do Departamento de Agricultura Norte-Americano (Beltsville, Maryland, EUA), apresentando incompatibilidade com 87 e 81 destes patótipos, respectivamente (Pastor-Corrales, 2001).

É interessante observar que os patótipos que apresentaram reações de compatibilidade com a cultivar Compuesto Negro Chimaltengo são provenientes de Santa Catarina e Rio Grande do Sul, enquanto que AxS 37 foi compatível com os isolados de Minas Gerais (Tabela 2). Os genes Andinos das cultivares Redlands Pioneer (Ur-13) e Brown Beauty (Ur-4) conferem também resistência a 41 e 40 isolados, respectivamente. Desta maneira, sugere-se que, com base nos seus espectros de resistência, as cultivares Redlands Pioneer, California Small White 643, Brown Beauty, AxS 37 e Compuesto Negro Chimaltenango, nesta ordem, sejam usados em programas de melhoramento que visem desenvolver variedades resistentes à ferrugem. Neste trabalho, a cultivar Redlands Pioneer se apresentou como resistente a todos os isolados analisados (graus de reação entre 1 e 3), sendo tais isolados oriundos de diferentes estados do Brasil (Tabela 2).

Por outro lado, a cultivar Kentucky Wonder 814 confere resistência somente aos patótipos identificados em Santa Catarina e no Rio Grande do Sul, enquanto que as cultivares Kentucky Wonder 765, Pinto Olathe e Kentucky Wonder 780 apresentaram resistência a 9, 9 e 8 dos 11 isolados provenientes de Goiás, respectivamente, sendo suscetíveis à maioria dos isolados das outras regiões. Já os alelos de $U r-3$ das cultivares 51051 e Mexico 235, e o gene $U r-5$ da cultivar Mexico 309, conferem resistência apenas aos patótipos identificados em Goiás e em Minas Gerais (Tabela 2). De acordo com as informações aqui apresentadas, pode-se inferir que no Brasil existe algum tipo de especialização geográfica da virulência apresentada pelas populações dos patótipos de U. appendiculatus analisados. Assim, em termos gerais, os genes de resistência das cultivares mencionadas anteriormente

TABELA 1 - Reações das cultivares diferenciadoras para ferrugem do feijoeiro comum (Phaseolus vulgaris) a sete isolados do fungo Uromyces appendiculatus coletados no Estado de Minas Gerais

\begin{tabular}{|c|c|c|c|c|c|c|c|c|}
\hline \multirow{3}{*}{\multicolumn{2}{|c|}{ Cultivar de Phaseolus vulgaris }} & \multicolumn{7}{|c|}{ Reações aos Isolados ${ }^{b}$} \\
\hline & & \multicolumn{7}{|c|}{ Patótipos $^{\mathrm{c}}$} \\
\hline & & 1 & 4 & 6 & 9 & 10 & 11 & 12 \\
\hline 1 & US 3 & 6 & 6 & 6 & 5,6 & 6 & 6 & 6,4 \\
\hline 2 & California Small White 643 & 2 & 1 & 2 & 2,3 & 2,1 & 1 & 1,2 \\
\hline 3 & Pinto 650 & 6 & 6 & 6 & 6 & 6 & 6 & 6 \\
\hline 4 & Kentucky Wonder 765 & 3 & 5 & 4,5 & 4 & $4,3,2,1$ & 4 & 2 \\
\hline 5 & Kentucky Wonder 780 & 6 & 5 & 4,6 & 3 & $6,5,4$ & 5,4 & $4,5,6$ \\
\hline 6 & Kentucky Wonder 814 & 6 & 6 & 6 & 6 & 6 & 6 & 6 \\
\hline 7 & Golden Gate Wax & 6 & 6 & 6 & 6 & 6 & 6 & 6 \\
\hline 8 & Early Gallatin & 5 & 6 & $6,4,2$ & 5,4 & 6,4 & 6 & $3,6,1,4$ \\
\hline 9 & Redlands Pioneer & 2 & 3 & $2,4,6,3,1$ & 3,1 & $1,2,3$ & 1,3 & 1 \\
\hline 10 & Ecuador 299 & 2 & 2 & 3,4 & 3,2 & $1,3,2$ & 2,3 & 1,2 \\
\hline 11 & Mexico 235 & 1 & 1 & 1,2 & 1 & 1 & 1 & 1 \\
\hline 12 & Mexico 309 & 1 & 1 & 1,2 & 1 & 1 & 1 & 1,3 \\
\hline 13 & Brown Beauty & 2 & 3 & 4,3 & 3,2 & $3,1,2$ & 3 & $1,2,3$ \\
\hline 14 & Pinto Olathe & 4 & 5 & 4,5 & 4 & 4,3 & 4,5 & 3,1 \\
\hline 15 & AxS 37 & 1 & 3 & 5,4 & 3,2 & $1,3,4,2$ & 4,3 & $1,2,3$ \\
\hline 16 & NEP-2 & 2 & 2 & 6,4 & 3,2 & $4,5,3$ & 5,4 & $3,4,1$ \\
\hline 17 & Aurora & 6 & 6 & 6 & 6,5 & 6 & 6 & 6 \\
\hline 18 & 51051 & 1 & 1 & 4 & 3,2 & $3,2,4$ & 4,3 & $3,4,1,2$ \\
\hline 19 & Compuesto Negro Chimaltenango & 2 & 1 & 3 & 3,2 & 1,3 & 2,3 & 1,2 \\
\hline TR & Ouro Negro & 1 & 1 & 1,3 & 2,3 & $3,1,2$ & 1 & 1,2 \\
\hline $\mathrm{TS}$ & US Pinto 111 & 6 & 6 & 6 & 6,5 & 6 & 6 & 6 \\
\hline
\end{tabular}

${ }^{a}$ Série padrão de cultivares diferenciadoras internacionais para Uromyces appendiculatus, agente causal da ferrugem do feijoeiro, adotada no "Primeiro Workshop Internacional sobre Ferrugem do Feijoeiro", realizado em Porto Rico, em 1983; cultivares testemunhas, resistente (TR) e suscetível (TS).

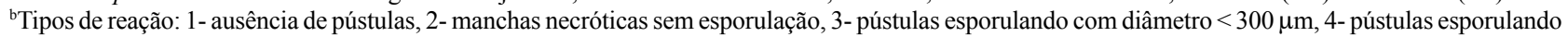
com diâmetro de $300 \mu \mathrm{m}$ a $499 \mu \mathrm{m}$, 5- pústulas esporulando com diâmetro de $500 \mu \mathrm{m}$ a $800 \mu \mathrm{m}$ e 6-pústulas esporulando com diâmetro $>800 \mu \mathrm{m}$. Onde aparece mais de um grau de reação, estes estão ordenados do mais ao menos prevalecente.

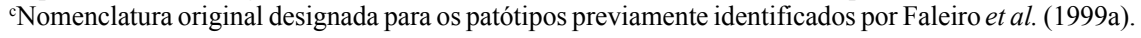


TABELA 2 - Análise comparativa da variabilidade patogênica de isolados de Uromyces appendiculatus coletados em diferentes Estados do Brasil

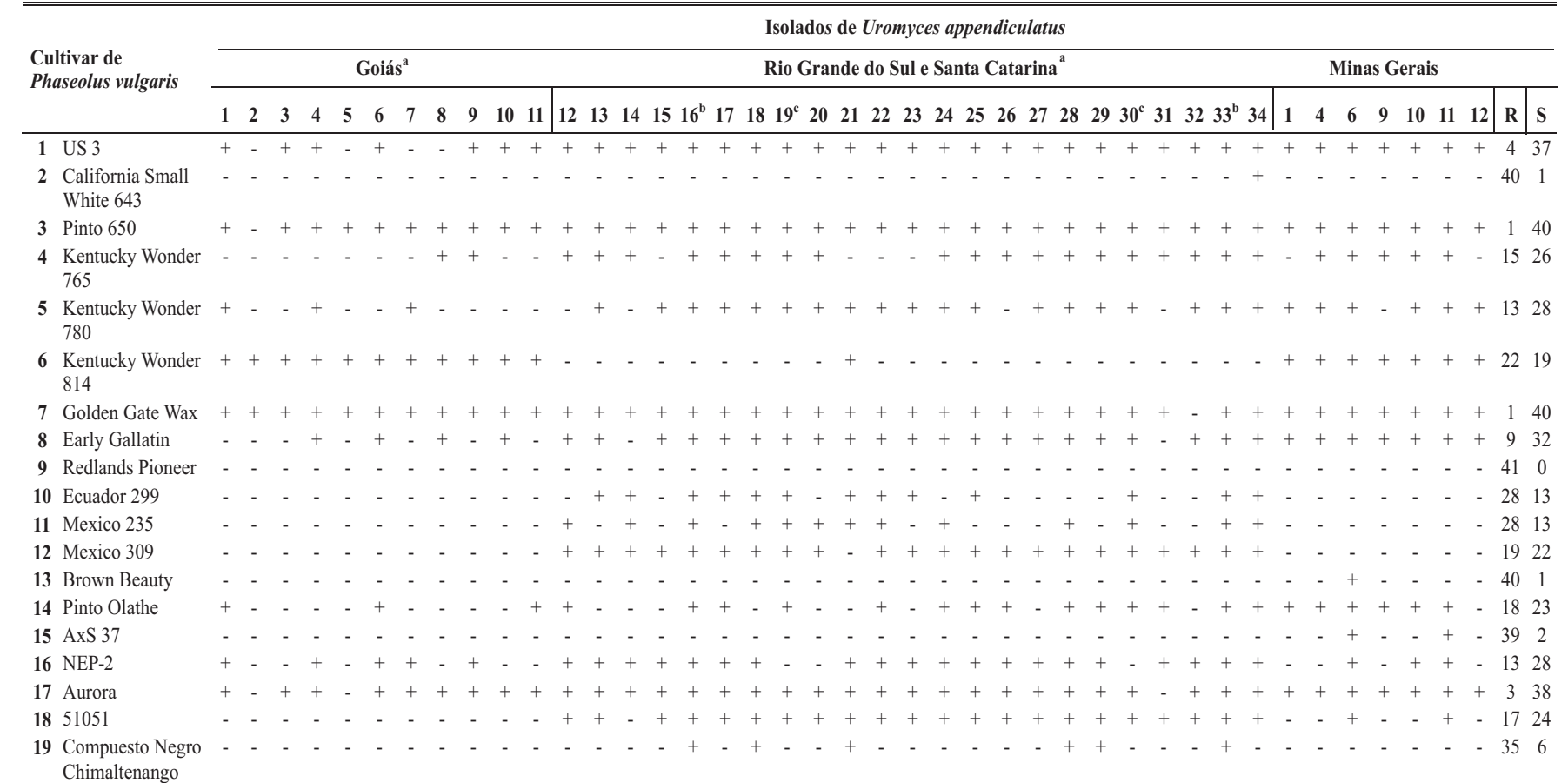

Patótipos

$\begin{array}{lllllllllllllllllllllllllllllllllllllllll}1 & 2 & 3 & 4 & 5 & 6 & 7 & 8 & 9 & 10 & 11 & 12 & 13 & 14 & 15 & 16 & 17 & 18 & 19 & 20 & 21 & 22 & 23 & 24 & 25 & 26 & 27 & 28 & 29 & - & 30 & 31 & - & 32 & 33 & 34 & 35 & 36 & 37 & 38 & 39\end{array}$

${ }^{a}$ No trabalho de Santos \& Rios (2000) são apresentadas as notas originais das reações de cada cultivar aos diferentes isolados. Para esta análise foram consideradas como resistentes, tanto no trabalho de Santos \& Rios (2000) como nos resultados do presente estudo (Tabela 1), os cultivares com notas de 1 a 3 (-), e suscetíveis os de notas entre 4 e $6(+)$, de acordo com a escala de avaliação adotada em ambos os trabalhos. Quando se observou mais de uma nota de avaliação na cultivar diferenciadora, foi considerada a primeira nota como a mais representativa, exceto no caso de nota 3 seguida de nota 6 , onde se estabeleceu tal caso como indicação de suscetibilidade.

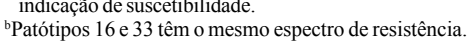

'Patótipos 19 e 30 têm o mesmo espectro de resistência 
podem ser usados em regiões especificas em associação (piramidação) com outras fontes de resistência de amplo espectro.

Maclean et al. (1995) e Sandlin et al. (1999) demonstraram a especialização da virulência de isolados de U. appendiculatus ao "pool" Andino de feijoeiro comum, mas também demonstraram a existência de isolados não específicos, os quais são compatíveis com os dois "pools" gênicos do feijoeiro. Nas análises realizadas neste trabalho, de uma forma geral, foi observado que os patótipos foram compatíveis com as cultivares dos "pools" gênicos Mesoamericano e Andino/Mesoamericano. Também, cultivares de origem Mesoamericana e Andina apresentaram resistência a quase todos os isolados analisados. Com estas evidências pode-se inferir que os isolados de $U$. appendiculatus analisados pertencem ao grupo de isolados não-específico (Tabela 2).

Com base nos resultados deste trabalho, reforça-se a importância da coleta e caracterização periódica de isolados de U. appendiculatus e do uso de todas as cultivares da série diferenciadora, além das escalas de avaliação internacionalmente definidas, para facilitar, assim, a comparação de patótipos identificados por diferentes grupos de pesquisa. No " 3 rd Bean Rust International Workshop", realizado na África do Sul, em 2002, foi definida uma nova série diferenciadora contendo seis cultivares Andinas e seis Mesoamericanas (Steadman et al., 2002). Nesse evento tambem foi redefinida uma metodologia para nomenclatura dos patótipos de $U$. appendiculatus, a qual é idêntica à utilizada atualmente para designar as raças do fungo Phaeoisariopsis griseola, agente causal da mancha angular do feijoeiro comum (PastorCorrales \& Jara, 1995). Nesta nova série diferenciadora, as cultivares Redland Pioneer e Compuesto Negro Chimaltenango foram mantidas, no entanto, as cultivares California Small White 643, AxS 37 e Brown Beauty foram excluídas. Apesar disso, recomenda-se que nas futuras caracterizações de patótipos a serem realizadas no Brasil, estas três cultivares sejam avaliadas juntamente com a série diferenciadora para que sejam mantidas as informações referentes à durabilidade da resistência dessas três importantes fontes.

\section{AGRADECIMENTOS}

Este trabalho foi financiado pelo CNPq e FAPEMIG. Por ocasião da realização do trabalho, Thiago Lívio Pessoa Oliveira de Souza era bolsista de Iniciação Científica do PIBIC-CNPq da Universidade Federal de Viçosa (UFV). Ana Lília Alzate-Marin era pesquisadora visitante da UFV e associada a EPAMIG, tendo sido financiada pela FAPEMIG.

\section{REFERÊNCIAS BILBLIOGRÁFICAS}

AGUSTIN, E. \& COSTA, J.G.C. Levantamento de raças fisiológicas de Uromyces phaseoli typica no Rio Grande do Sul e Santa Catarina em 1968 e 1969. Pesquisa Agropecuária Brasileira Serie Agronômica 6:137-138. 1971.

CARRIJO, I.V., CHAVES, G.M. \& PEREIRA, A.A. Reação de vinte e cinco variedades de Phaseolus vulgaris a trinta e nove raças fisiológicas de Uromyces phaseoli var. typica Arth., em condições de casa-de-vegetação. Fitopatologia Brasileira 5:245-255. 1980.

CASTAÑO, J. Manual standar para cuantificación de daños causados por hongos, bacterias y nematodos en frijol. (Mimeografado). Cali, Colômbia. CIAT. 1985.

COELHO, R.S.B. \& CHAVES, G.M. Comparação de dois métodos de amostragens na identificação de raças de Uromyces appendiculatus typica Arth. Experientiae 19:149-186. 1975.

CUMINS, G.B. Rust fungi on legumes and composites in North America. Tucson:University of Arizon Press. 1978.

DIAS, I.R. \& COSTA, J.C.C. Identificação de raças fisiológicas de ferrugem (Uromyces phaseoli typica Arth.) do feijoeiro (Phaseolus vulgaris L.) em duas regiões fisiográficas do Rio Grande do Sul, Brasil. Pesquisa Agropecuária Brasileira Serie Agronômica 3:165170. 1968.

FALEIRO, F.G., VINHADELLI, W.S., RAGAGNIN, V.A., ZAMBOLIM, L., PAULA JÚNIOR, T.J., MOREIRA, M.A. \& BARROS, E.G. Identificação de raças fisiológicas de Uromyces appendiculatus no estado de Minas Gerais, Brasil. Fitopatologia Brasileira 24:166-169. 1999a.

FALEIRO, F.G., ZAMBOLIM, L., VINHADELLI, W.S., RAGAGNIN, V.A., PAULA JÚNIOR, T.J., MOREIRA, M.A. \& BARROS, E.G. Sistema simplificado para nomenclatura e classificação de raças fisiológicas de Uromyces appendiculatus. Fitopatologia Brasileira 24:540-545. 1999b.

GROTH, J.V. \& OZMON, E.A. Contrasting effects of assexual reprodution and random mating on changes in virulence frequency in a field collection of Uromyces appendiculatus. Phytopathology 84:566-569. 1994.

JUNQUEIRA NETTO, A., ATHOW, K.L. \& VIEIRA, C. Identificação de raças fisiológicas de Uromyces phaseoli no Estado de Minas Gerais. Revista Ceres 16:1-9. 1969.

LINDGREN, D.T., ESCRIDGE, K.M., STEADMAN, J.R. \& SCHAAF, D.M. A model for dry bean yield loss due to rust. Hort Tecnology 5:35-37. 1995.

MACLEAN, D.J., BRAITHWAITE, K.S., IRWIN, J.A.G., MANNERS, J.M., \& GROTH, J.V. Random amplified polymorphic DNA reveals relationships among diverse genotypes in Australian and American collections of Uromyces appendiculatus. Phytopathology 85:757-765. 1995.

MORA-NUÑES, O.A., VIEIRA, C. \& ZAMBOLIM, L. Variedades diferenciadoras de feijão para identificação de raças fisiológicas de Uromyces phaseoli var. typica Arth. Revista Ceres 39:391-404. 1992.

PAULA JÚNIOR, T.J. \& ZAMBOLIM, L. Doenças. In: Vieira, C., Paula Júnior, T.J. \& Borém, A. (Eds.) Feijão:Aspectos gerais e cultura no Estado de Minas Gerais. Viçosa: Editora UFV. 1998. pp.375-433.

PASTOR-CORRALES, M.A. The reaction of 19 bean rust differential cultivars to 94 races of Uromyces appendiculatus and the implication for the development of rust resistance cultivars. Annual Report of the Bean Improvement Cooperative 44:103-104. 2001.

PASTOR-CORRALES, M.A. \& JARA, C.E. La evolucion de $P$. griseola con el frijol comun en America Latina. Fitopatologia 
Ánálise comparativa da variabilidade patogênica de Uromyces appendiculatus...

Colombiana 19:15-23. 1995.

SANTOS, S.C. \& RIOS, G.P. Identificação de raças fisiológicas de Uromyces appendiculatus nos Estados de Goiás, Rio Grande do Sul e Santa Catarina. Fitopatologia Brasileira 25:607-611. 2000.

SANDLIN, C.M., STEADMAN, J.R. \& ARAYA, C.M. Isolates of Uromyces appendiculatus with specific virulence to landraces of Phaseolus vulgaris of Andean origin. Plant Disease 83:108-113. 1999.

STAVELY, J.R., FREYTAG, G.F., STEADMAN, J.R. \& SCHWARTZ, H.F. The 1983 Bean Rust Workshop. Annual Report of the Bean Improvement Cooperative 26:iv-vi. 1983.
STAVELY, J.R. Pathogenic specialization in Uromyces phaseoli in the United States and rust resistance in beans. Plant Disease 68:9599. 1984.

STEADMAN, J.R., PASTOR-CORRALES, M.A. \& BEAVER, J.S. An overview of the $3^{\text {rd }}$ bean rust and $2^{\text {nd }}$ bean common bacterial blight international workshops, march 4-8, 2002, Pietermaritzburg, South Africa. Annual Report of the Bean Improvement Cooperative 45:120-125. 2002.

VIEIRA, C. Doenças e pragas do feijoeiro. $2^{\mathrm{a}}$ ed. Viçosa: Editora UFV. 1988. 